\title{
Sarcoma of the Uterus. Guideline of the DGGG (S2k-Level, AWMF Registry No. 015/074, August 2015)
}

\author{
Uterine Sarkome. Leitlinie der DGGG (S2k-Level, \\ AWMF-Registernummer 015/074, August 2015)
}

Authors

Affiliations
D. Denschlag ${ }^{1}$, F. C. Thiel ${ }^{2}$, S. Ackermann ${ }^{3}$, P. Harter ${ }^{4}$, I. Juhasz-Boess ${ }^{5}$, P. Mallmann ${ }^{6}$, H.-G. Strauss ${ }^{7}$, U. Ulrich ${ }^{8}$, L.-C. Horn ${ }^{9}$, D. Schmidt ${ }^{10}$, D. Vordermark ${ }^{11}$, T. Vogl ${ }^{12}$, P. Reichardt ${ }^{13}$, P. Gaß ${ }^{14}$, M. Gebhardt ${ }^{15}$, M. W. Beckmann ${ }^{14}$

The affiliations are listed at the end of the article.

\section{Key words \\ - uterine sarcoma \\ - guideline \\ - leiomyosarcoma \\ - endometrial stromal sarcoma \\ - carcinosarcoma \\ Schlüsselwörter \\ - uterine Sarkome \\ - Leitlinie \\ - Leiomyosarkom \\ - endometriale \\ Stromasarkome \\ - Karzinosarkom

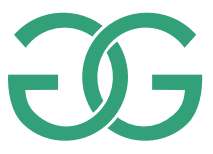 \\ OEGGG}

\section{gynécologie \\ suisse}

Deutsche Version unter: www.thieme-connect.de/ ejournals/gebfra

Bibliography

DOI http://dx.doi.org/

10.1055/s-0035-1558120

Geburtsh Frauenheilk 2015; 75 :

1028-1042 @ Georg Thieme

Verlag KG Stuttgart · New York . ISSN 0016-5751

\section{Correspondence}

Prof. Dr. med.

Dominik Denschlag

Hochtaunus-Klinik-gGmbH

Zeppelinstraße 20

61352 Bad Homburg

dominik.denschlag@

hochtaunus-kliniken.de

\section{Abstract}

$\boldsymbol{\nabla}$

Purpose: Official guideline published and coordinated by the German Society of Gynecology and Obstetrics (DGGG). Due to their rarity and their heterogeneous histopathology uterine sarcomas remain challenging tumors to manage and need a multidisciplinary approach. To our knowledge so far there is no evidence-based guideline on the appropiate management of these heterogeneous tumors.

Methods: This S2k-guideline is the work of an representative committee of experts from a variety of different professions who were commissioned by the DGGG to carry out a systematic literature review of uterine sarcoma. Members of the participating scientific societies developed a structured consensus in a formal procedure.

Recommendations: 1 . The incidence and histopathologic classification of uterine sarcoma. 2. The clinical manifestations, diagnosis and staging of uterine sarcoma. 3. The management of leiomyosarcoma. 4 . The management of endometrial stromal sarcoma and undifferentiated uterine sarcoma. 5. The management of adenosarcoma as well as carcinosarcomas. 6. The management of morcellated uterine sarcoma

\section{Guideline Information}

Guidelines Program of the DGGG, OEGGG and SGGG

Information on this topic is provided at the end of the guideline.

\section{Zusammenfassung \\ $\nabla$}

Ziel: Offizielle Leitlinie, publiziert und koordiniert von der Deutschen Gesellschaft für Gynäkologie und Geburtshilfe (DGGG). Aufgrund ihrer Seltenheit und heterogenen Histopathologie stellen uterine Sarkome eine Herausforderung bzgl. des klinischen Managements dar und bedürfen von daher einem multidisziplinären Ansatz. Nach unserem Kenntnisstand existieren bis dato keine verbindlichen, evidenzbasierten Empfehlungen bzgl. des angemessenen Managements dieser heterogenen Tumore.

Methoden: Die vorliegende S2k-Leitlinie ist das Ergebnis der Arbeit eines repräsentativen interdisziplinären Experten-Komitees, welches im Auftrag der Leitlinienkommission der DGGG eine systematische Literaturrecherche zum Thema Uterine Sarkome durchgeführt hat. Mitglieder der beteiligten Fachgesellschaften entwickelten in einem strukturierten Prozess einen formalen Konsensus.

Empfehlungen: 1. Die Inzidenz und histopathologische Klassifikationen von uterinen Sarkomen. 2. Die klinische Symptomatik, Diagnostik und Stadieneinteilung von uterinen Sarkomen. 3. Das Management von Leiomyosarkome. 4. Das Management von endometrialen Stromasarkomen und undifferenzierten uterinen Sarkomen. 5. Das Management von Adenosarkomen als auch Karzinosarkomen. 6. Das Management von morcellierten uterinen Sarkomen

\section{Citation format}

Sarcoma of the Uterus. Guideline of the DGGG (S2k-Level, AWMF Registry No. 015/074, August 2015). Geburtsh Frauenheilk 2015; 75: 10281042 
Table 1 Authors.

\begin{tabular}{|c|c|}
\hline $\begin{array}{l}\text { Author } \\
\text { Mandate holder }\end{array}$ & $\begin{array}{l}\text { DGGG working group/professional } \\
\text { association/organization/society }\end{array}$ \\
\hline \multicolumn{2}{|l|}{ Coordinating lead author: } \\
\hline Prof. Dr. med. Dominik Denschlag & $\begin{array}{l}\text { German Society of Gynecology and } \\
\text { Obstetrics (Deutsche Gesellschaft für } \\
\text { Gynäkologie und Geburtshilfe [DGGG]) }\end{array}$ \\
\hline \multicolumn{2}{|c|}{ Other participating authors contributing to the guideline: } \\
\hline Prof. Dr. med. & German Society of Gynecology and \\
\hline Matthias W. Beckmann & $\begin{array}{l}\text { Obstetrics (Deutsche Gesellschaft für } \\
\text { Gynäkologie und Geburtshilfe [DGGG]) }\end{array}$ \\
\hline PD Dr. med. Falk C. Thiel & $\begin{array}{l}\text { German Society of Gynecology and } \\
\text { Obstetrics (Deutsche Gesellschaft für } \\
\text { Gynäkologie und Geburtshilfe [DGGG]) }\end{array}$ \\
\hline PD Dr. med. Sven Ackermann & $\begin{array}{l}\text { Working Group Gynecologic Oncology } \\
\text { (Arbeitsgemeinschaft Gynäkologische } \\
\text { Onkologie [AGO]) }\end{array}$ \\
\hline PD Dr. med. Ingolf Juhasz-Boess & $\begin{array}{l}\text { Working Group Gynecologic Oncology } \\
\text { (Arbeitsgemeinschaft Gynäkologische } \\
\text { Onkologie [AGO]) }\end{array}$ \\
\hline PD Dr. med. Philipp Harter & $\begin{array}{l}\text { Working Group Gynecologic Oncology } \\
\text { (Arbeitsgemeinschaft Gynäkologische } \\
\text { Onkologie [AGO]) }\end{array}$ \\
\hline Prof. Dr. med. Peter Mallmann & $\begin{array}{l}\text { Working Group Gynecologic Oncology } \\
\text { (Arbeitsgemeinschaft Gynäkologische } \\
\text { Onkologie [AGO]) }\end{array}$ \\
\hline Dr. med. Hans-Georg Strauß & $\begin{array}{l}\text { Working Group Gynecologic Oncology } \\
\text { (Arbeitsgemeinschaft Gynäkologische } \\
\text { Onkologie [AGO]) }\end{array}$ \\
\hline Prof. Dr. med. Uwe Ulrich & $\begin{array}{l}\text { Working Group Gynecologic Oncology } \\
\text { (Arbeitsgemeinschaft Gynäkologische } \\
\text { Onkologie [AGO]) }\end{array}$ \\
\hline Prof. Dr. med. Lars-Christian Horn & $\begin{array}{l}\text { German Society of Pathology (Deutsche } \\
\text { Gesellschaft für Pathologie [DGP]) }\end{array}$ \\
\hline $\begin{array}{l}\text { Prof. Dr. med. Dr. h.c. } \\
\text { Dietmar Schmidt }\end{array}$ & $\begin{array}{l}\text { German Society of Pathology (Deutsche } \\
\text { Gesellschaft für Pathologie [DGP]) }\end{array}$ \\
\hline PD Dr. med. Peter Reichardt & $\begin{array}{l}\text { German Society of Haematology and } \\
\text { Oncology (Deutsche Gesellschaft für } \\
\text { Hämatologie und Medizinische Onkolo- } \\
\text { gie [DGHO]) }\end{array}$ \\
\hline Prof. Dr. med. Thomas Vogel & $\begin{array}{l}\text { German Society of Radiology } \\
\text { (Deutsche Röntgengesellschaft [DRG]) }\end{array}$ \\
\hline Prof. Dr. med. Dirk Vordermark & $\begin{array}{l}\text { German Society of Radiooncology } \\
\text { (Deutsche Gesellschaft für Radio- } \\
\text { onkologie [DEGRO]) }\end{array}$ \\
\hline Dr. med. Wolfgang Cremer & $\begin{array}{l}\text { Federal Association of Gynecologists } \\
\text { (Bundesverband der Frauenärzte e. V. } \\
\text { [BFV]) }\end{array}$ \\
\hline Marion Gebhardt & $\begin{array}{l}\text { „Bundesverband Selbsthilfegruppe } \\
\text { Frauen nach Krebs e.V.“ (Support Group } \\
\text { for Women Cancer Survivors [FSH]) }\end{array}$ \\
\hline
\end{tabular}

\section{Guideline documents}

The editorially complete long version and a PDF slide set suitable for PowerPoint presentations of these guidelines as well as a summary of the conflicts of interest of all the authors can be found on the homepage of AWMF:

http://www.awmf.org/leitlinien/detail/11/015-074.html

\section{Authors}

\section{See $\bigcirc$ Table 1.}

\section{Abbreviations}

LMS leiomyosarcoma

LG-ESS low-grade endometrial stromal sarcoma
HG-ESS high-grade endometrial stromal sarcoma

UUS undifferentiated uterine sarcoma

\section{Using this Guideline}

\section{Purpose and objectives}

Because of the biological heterogeneity of uterine sarcomas (including carcinosarcomas) and the widespread uncertainty regarding the optimal management of individual cases, a guideline was considered necessary to improve the quality of care offered to patients.

\section{Patient care}

The guideline aims to provide information on the advice and counseling offered to women and on the diagnosis, treatment and follow-up of uterine sarcoma. The focus is on the differentiated management of the different subtypes (including carcinosarcoma). The information should also serve as the basis for treatment decisions taken by interdisciplinary tumor boards in the gynecological cancer centers currently being established.

\section{Target audience}

The guideline is aimed at the following groups of people:

- The recommendations of this guideline are addressed to all physicians (in particular, gynecologists, pathologists, radiotherapists and medical oncologists) and healthcare professionals involved in the care of patients with uterine sarcomas (including carcinosarcoma);

- It is addressed to professionals working in an inpatient or an outpatient setting.

\section{Period of validity}

The validity of this guideline was confirmed by the chairpersons/ heads of the participating medical societies/organizations/associations and by the head of the DGGG and the DGGG Guideline Commission in July 2015, thereby also confirming the entire contents of the guideline. This guideline is valid from August 1, 2015 to July 31,2018 . This period of validity was estimated based on the contents of the guideline. If need be, the guideline can be updated before it has expired; if the guideline is still considered to represent the current state of knowledge, its period of validity can be extended.

\section{Guideline}

\section{Methodology}

The methodology for the compilation of this guideline is prescribed by the classification assigned to the guideline. The AWMF Guidance Manual and Rules for Guideline Development (Version $1.0)$ sets out the rules for classifying guidelines. Guidelines are differentiated into lowest (S1), moderate (S2) and highest (S3) class. The lowest class of guideline is defined as consisting of a set of recommendations for action compiled by a representative group of experts from medical societies. In 2004 the S2 class was divided into two subclasses: S2e (evidence-based) and S2k (consensus-based). The highest class (S3) combines both approaches.

\section{This guideline is classified as $\mathbf{S 2} \mathbf{k}$.}

The text of the guideline is based on a systematic search of the literature. The relevant literature was allocated to the appropriate chapters, and the chapters including the literature were then 
Table 2 FIGO/TNM staging of uterine leiomyosarcomas and endometrial stromal sarcomas*.

\begin{tabular}{|c|c|c|}
\hline \multicolumn{2}{|c|}{ FIGO/TNM stage } & Definition \\
\hline \multirow[t]{3}{*}{ I/T1 } & & tumor limited to the uterus \\
\hline & $\mathrm{IA} / \mathrm{T} 1 \mathrm{a}$ & $\leq 5 \mathrm{~cm}$ at its largest diameter \\
\hline & $\mathrm{IB} / \mathrm{T} 1 \mathrm{~b}$ & $>5 \mathrm{~cm}$ at its largest diameter \\
\hline \multirow[t]{3}{*}{$11 / \mathrm{T} 2$} & & tumor extends beyond the uterus to the pelvis \\
\hline & IIA/T2a & $\begin{array}{l}\text { involvement of the adnexa of the uterus } \\
\text { (unilateral or bilateral) }\end{array}$ \\
\hline & $\mathrm{IIB} / \mathrm{T} 2 \mathrm{~b}$ & $\begin{array}{l}\text { tumor spread to extrauterine pelvic tissue } \\
\text { excluding the adnexa }\end{array}$ \\
\hline III/T3 & & tumor has infiltrated abdominal tissues \\
\hline \multirow[t]{3}{*}{ N1 } & IIIA/T3а & one site \\
\hline & $\mathrm{IIIB} / \mathrm{T} 3 \mathrm{~b}$ & more than one site \\
\hline & IIIC & $\begin{array}{l}\text { metastasis to the pelvic and/or para-aortic } \\
\text { lymph nodes }\end{array}$ \\
\hline \multirow[t]{2}{*}{ IVT4 } & IVA/T4 & tumor has infiltrated the bladder and/or rectum \\
\hline & IVB & distant metastasis \\
\hline
\end{tabular}

* Synchronous tumors of the uterine body and the ovary/pelvis accompanied by endometriosis of the ovary/pelvis should be classified as independent primary tumors.

sent to the respective lead authors. Subsequently, a cohesive draft version of the guideline was compiled based on the individual chapters, and this draft version was reworked and adopted in a joint advance consensus process. Statements and recommendations (i.e., clear recommendations for action) were then extrapolated from this text. The revised text was circulated again and sent to representatives from other medical specialties, some of whom proposed amendments to the text; at the conclusion of this process the final manuscript was agreed upon. The statements and recommendations were voted on in an interdisciplinary consensus conference held on May 20, 2015 in Berlin. The Guideline Commission and the head of the DGGG approved the guideline in August 2015.

\section{Introduction}

\subsection{Incidence, tumor typing}

or classification and staging

Uterine sarcoma is the term used to describe a heterogeneous group of rare malignant tumors of the uterine musculature or connective tissue. They comprise $3-9 \%$ of all malignant uterine tumors. The incidence of uterine sarcoma is between 1.5 (Caucasians) and 3 (Afro-Americans) per 100000 population [1].

Tumor typing is done using the WHO classification; staging is based on the FIGO and TNM classification [2,3]. The WHO classification lists the following entities as malignant mesenchymal tumors or malignant mixed epithelial-mesenchymal tumors $[3,4]$ :

- leiomyosarcoma (LMS),

- low-grade endometrial stromal sarcoma (LG-ESS),

- high-grade endometrial stromal sarcoma (HG-ESS),

- undifferentiated uterine sarcoma (UUS),

- adenosarcoma,

- rhabdomyosarcoma,

- PECome (perivascular epithelioid cell tumor), malignant type.

The most important morphological characteristics of the different entities are described briefly below.

The diagnosis of other rare uterine sarcomas is done based on the WHO classification of soft tissue sarcomas [5].
Table 3 FIGO/TNM staging of uterine adenosarcomas*.

\begin{tabular}{|c|c|c|}
\hline \multicolumn{2}{|c|}{ FIGO/TNM stage } & Definition \\
\hline \multirow[t]{4}{*}{$\mathrm{I} / \mathrm{T} 1$} & & tumor limited to the uterus \\
\hline & IA/T1a & $\begin{array}{l}\text { tumor limited to the endometrium/ } \\
\text { endocervix without myometrial infiltration }\end{array}$ \\
\hline & $\mathrm{IB} / \mathrm{T} 1 \mathrm{~b}$ & infiltration less than half of the myometrium \\
\hline & IC/T1C & infiltration $\geq 50 \%$ of the myometrium \\
\hline \multirow[t]{3}{*}{$\mathrm{II} / \mathrm{T} 2$} & & tumor spread in the pelvis \\
\hline & IIA/T2a & adnexal involvement (unilateral or bilateral) \\
\hline & IIB/T2b & $\begin{array}{l}\text { tumor spread to extrauterine pelvic tissue } \\
\text { excluding the adnexa }\end{array}$ \\
\hline III/T3 & & intra-abdominal tumor spread \\
\hline \multirow[t]{3}{*}{ N1 } & IIIA/T3a & one site \\
\hline & IIIB/T3b & more than one site \\
\hline & IIIC & $\begin{array}{l}\text { metastasis to the pelvic and/or para-aortic } \\
\text { lymph nodes }\end{array}$ \\
\hline \multirow[t]{2}{*}{ IV/T4 } & IVA/T4 & $\begin{array}{l}\text { tumor has infiltrated the bladder and/or } \\
\text { rectal mucosa }\end{array}$ \\
\hline & IVB & distant metastasis \\
\hline
\end{tabular}

* Synchronous tumors of the uterine body and the ovary/pelvis accompanied by endometriosis of the ovary/pelvis should be classified as independent primary tumors.

In addition to extremely rare forms of sarcoma (rhabdomyosarcoma, angiosarcoma, neurogenic sarcoma, osteosarcoma, chondrosarcoma, liposarcoma, PNET, PECome, myxofibrosarcoma, alveolar soft tissue sarcoma and epithelioid sarcoma), this guideline will be focusing on the more common entities (LMS, LG-ESS, HG-ESS and UUS or adenosarcoma).

Leiomyosarcomas are the most common type and constitute 60$70 \%$ of uterine sarcomas and $1-2 \%$ of all malignant uterine tumors, followed by low-grade ESS, high-grade ESS and undifferentiated uterine sarcomas, which respectively account for around $10 \%$ of uterine sarcomas. Less common sarcomas include adenosarcomas and other heterologous sarcomas (fibrosarcomas, liposarcomas, chondrosarcomas, osteosarcomas, etc.) which together make up just under $5 \%$ of uterine sarcomas [6]. The mean age at onset of uterine disease is $50-70$ years depending on the tumor type. Identified risk factors include previous pelvic irradiation therapy and prior treatment with tamoxifen. The incidence of uterine sarcomas is 2-3 higher in women of African descent compared to women of Asian or European descent.

Postoperative staging is done using the pTNM [2] and FIGO classification systems ( 0 Tables $\mathbf{2}$ and $\mathbf{3}$ ).

Uterine carcinosarcomas (also referred to as malignant mixed Müllerian tumors) were previously classified as a subtype of uterine sarcoma but are now considered uterine carcinomas [7, 8]. However, as this entity has not been adequately discussed in other guidelines, it is included in the present guideline. In the medium term it is planned that it will be covered in the upcoming S3-guideline on endometrial carcinomas.

With an incidence of around 2-4 per 100000 population, the incidence of uterine carcinosarcomas is slightly higher than that of uterine sarcomas. The mean age at onset of disease (around 65 years) also appears to be slightly higher, whereas the postulated risk factors (tamoxifen intake, prior exposure to pelvic radiotherapy, Afro-American descent, s. above) appear to correspond to those of classic sarcomas.

The overall prognosis for carcinosarcoma is poor, with a mean 5year survival rate of just $30 \%$. The tumor stage is the most important prognostic factor for carcinosarcoma along with age, ethnic origin and tumor grade [9-12]. 


\subsection{Diagnosis}

There are no specific symptoms associated with uterine sarcomas. Suspicious symptoms include rapid uterine growth in postmenopausal women with low estrogen levels. Because of the absence of specific symptoms the majority of cases are detected either incidentally when examining the resected specimen after hysterectomy or after disease is already in an advanced stage with the appearance of secondary accompanying symptoms (e.g. dyspnea due to pulmonary metastasis). With regard to the risk of sarcoma in patients with rapid uterine growth (e.g. [13], an increase in size corresponding to 6 weeks of pregnancy within the space of just one year) a study by Parker and colleagues of more than 1300 patients (of whom around 350 had rapid growth) did not find an increased risk of sarcoma compared to controls $(0.27$ vs. $0.23 \%$ ) [14]. Symptoms in around $2 / 3$ of cases consisted of pathological vaginal bleeding [15]. In contrast to carcinomas, hysteroscopy and curettage do not always result in diagnosis. Findings in patients with mesenchymal uterine tumors may often be false negative, i.e., the latter entities often remain undetected in cases with bleeding disorder or postmenopausal bleeding requiring histological analysis. These diagnostic methods are therefore not able to exclude uterine sarcoma $[16,17]$.

Morcellation procedures are contraindicated if there is a clinical suspicion of malignant uterine disease, as this approach can worsen prognosis [18]. Patients must be informed about the risk and offered alternative procedures in all cases of planned morcellation, even if the tumor does not appear to be clinically suspicious.

\section{Imaging}

Imaging procedures to diagnose uterine sarcomas include evaluating the appearance of the uterine mass to differentiate the mass from other pelvic masses. Radiological diagnostic procedures are used to evaluate the depth of invasion, the extent of infiltration of adjacent organs, lymph node involvement and the presence of other pelvic metastasis.

In addition to ultrasound, which is currently the diagnostic procedure of choice for imaging of the uterus, MRI offers a high diagnostic sensitivity and specificity through the use of diffusionweighted sequences (DWI sequences) and contrast-enhanced sequences [19]. Imaging criteria for uterine anomalies are based on the evaluation of necrotic areas and the growth and extent of the lesion. Abdominal imaging is done using computed tomography to capture abdominal masses, evaluate lymph node invasion, the infiltration of organs such as the liver, spleen, peritoneum, and constrictions in different sections of the intestine.

Sadeghi et al. [20] provided an overview of the current role of positron emission tomography (FDG-PET) for the imaging of uterine sarcomas. The review analyzed 8 studies. Only 2 of the studies provided detailed data on the primary staging of uterine sarcoma with limited sensitivity for the detection of lymph nodes. The role of PET-CT in detecting recurrent disease was also evaluated by Sharma et al. [21] in 15 procedures done in 12 patients. Their study showed that currently PET/CT does not offer more information than conventional CT or MRI procedures.

In summary, further studies are needed. Primary use of PET/CT cannot be currently recommended to obtain a primary diagnosis of uterine sarcoma.

Ultrasound is currently the primary diagnostic procedure for evaluation of the uterus. The use of MRI to show the extent of local spread and detect local tumor infiltration is recommended.
For the abdomen there are currently no scientific data demonstrating better diagnostics and results using MRI compared to CT. Because of the high potential for metastasis it is also important to perform a CT scan of the thorax.

\section{Tissue preparation and analysis}

Curettage material and diagnostic biopsy

The diagnosis of uterine sarcoma requires the removal of representative tissue samples. If findings in the curettage material are morphologically suspicious for sarcoma and further lab samples are available, then preparing and embedding this material can provide useful information. Tissue removed by core-needle biopsy for histological examination should be in cut into sections for examination. Three sections cut at distances of around $200 \mu \mathrm{m}$ are usually sufficient.

The definitive histogenetic classification of uterine sarcomas can be difficult if there are regressive changes or extensive necrotic areas in the curettage material or biopsy sample. Samples must be carefully analyzed using immunohistochemistry and, where necessary, molecular pathology procedures, as definitive surgery may be problematic in patients with (locally) advanced disease or patients with an increased risk of morbidity or anesthesia complications, and tissue findings then become relevant for therapy. The pathology report must include details of any lymph node or vascular invasion [3,22-24].

Specimens after hysterectomy or surgery

for uterine sarcoma

The pathological report must include information on the size and condition of the specimen (integrity of the specimen, morcellation) together with details of the resected structures $[3,23,24]$. It is important to pay particular attention to abnormal macroscopic findings (e.g. discoloration, hemorrhage, bleeding, poorly differentiated foci) if the uterus is removed by morcellation/in several segments and to ensure that removal of tissue samples is adequate [25].

Morphological examination must include all of the following points [3,22-24].

- histological tumor type according to WHO classification

- ESS grade

- detection/absence of lymph node or vascular invasion (lymph node and vascular status)

- detection/absence of perineural sheath infiltration (perineural status)

- stage (pTNM)

- depth of invasion of the myometrium or (endo-)cervical stroma

- three-dimensional tumor size in $\mathrm{cm}$

- minimal distance between the sarcoma and the respective resection margin

- residual tumor $(\mathrm{R})$ classification (UICC)

Measurement of the distance to the respective resection margin is done from the point of deepest tumor invasion to the surgical resection margin, after marking of the specimen slide using either a ruler or an ocular micrometer for very small distances. If the histological findings are unclear, extensive tumor sampling is necessary. This usually consists of one block per centimeter on the side of greatest tumor extension.

All patients with a diagnosis of uterine sarcoma should be presented and discussed in an interdisciplinary tumor board. 


\section{Uterine Carcinosarcoma| Malignant Mixed Müllerian Tumor}

\subsection{Introduction}

Carcinosarcomas (also referred to as malignant mixed Müllerian tumors), formerly also classified as uterine sarcomas, are now as mentioned above - no longer categorized as a subtype of uterine sarcoma but believed to be uterine carcinomas. In the current view, they are metaplastic, dedifferentiated endometrial carcinomas. Based on this categorization, staging is done analogously to that for endometrial carcinomas $[2,26]$.

The mean age at onset of disease is in the 7th decade of life (range 30-90 years) [27]. Pathological bleeding is more likely to occur with these entities - presumed to be dedifferentiated endometrial carcinomas - than with sarcomas, sometimes associated with enlarged uterus and related symptoms. There are no specific diagnostic signs for carcinosarcoma/malignant mixed Müllerian tumor on imaging (ultrasound, CT, MRI). Around $25 \%$ of patients already have distant metastasis at the time of primary diagnosis; lymph node (pelvic and/or para-aortic) involvement is present in up to $30 \%$ [28]. Because this tumor entity is often only found when disease is already in an advanced stage, levels of the tumor marker CA-125 are often increased at the time of diagnosis. The evaluation of curettage material is often difficult and may present only as a malignant component [16]. The definitive diagnosis is often only possible after examination of the resected uterus following hysterectomy.

The 5-year survival rate depends largely on the initial stage at presentation; it is around $50-60 \%$ for patients with stages I/II disease and drops significantly for advanced stage tumors (stage III/ IV - approx. 10-20\%).

\subsection{Histopathological diagnosis and staging}

Carcinosarcomas are tumors which consist histologically of both a malignant epithelial (carcinomatous) component and a malignant mesenchymal (sarcomatous) component [29]. Common synonyms include the terms malignant mixed Müllerian tumor (MMMT), malignant mixed mesodermal tumor, and metaplastic carcinoma [30].

Homologous MMMTs include mesenchymal elements composed of tissues normally found in the uterus (so-called intrinsic differentiation). The homologous mesenchymal component may include endometrial stromal sarcoma, undifferentiated sarcoma, fibrosarcoma or leiomyosarcoma or a mixture of these entities. The heterologous type can include sarcomatous components which are not normally found in the uterus in their benign form (so-called extrinsic differentiation [30]). In descending order of frequency they include rhabdomyosarcoma and chondrosarcoma, more rarely osteosarcoma and liposarcoma. Neuroectodermal, melanocytic, neuroendocrine, rhabdoid and yolk sac differentiation are extremely rare [31-35].

The malignant epithelial (carcinomatous) component is usually glandular in origin [29]. But non-glandular components such as squamous cell or undifferentiated carcinoma also occur. The glandular component usually corresponds to endometrioid endometrial carcinoma, in more rare cases to so-called type-2 carcinoma with serous or clear cell morphology.

Differentiating MMMT with a pronounced mesenchymal component (sarcomatous overgrowth) from uterine sarcoma can be difficult, highlighting the importance of a proper pathological-anatomical work-up [30].

\subsection{Surgery}

Total removal of the uterus and of both adnexa is the gold standard of surgical management in patients with early-stage uterine carcinosarcoma. Similar to high-risk endometrial carcinoma, a number of retrospective data analyses have reported that systematic lymphadenectomy has a positive effect on overall patient survival; up to $30 \%$ of patients with macroscopic disease limited to the uterus were found to have a positive lymph node status [11, $12,36,37]$. The current literature does not show that additional omentectomy, as proposed by other panels of experts for entities with serous epithelial component (www.nccn.org), is beneficial. Cytoreductive surgery may be performed in patients with advanced stage disease if complete resection appears achievable; however the data on this point is limited [38].

\subsection{Adjuvant systemic therapy and radiotherapy}

A randomized phase III study of 232 patients with carcinosarcoma showed that adjuvant combined chemotherapy with cisplatin/ifosfamide reduced the risk of dying during the 5-year follow-up period by $29 \%$ compared to whole abdominal irradiation in patients with FIGO stage I-IV disease and postoperative residual tumor of $<1 \mathrm{~cm}$; the benefit was not statistically significant [39]. Other data from retrospective studies appear to indicate that this therapy can also have a positive effect on patients with early-stage (I and II) disease [40].

The decision for adjuvant chemotherapy must be discussed with the patient on an individual basis; it must take account of findings and the patient must be given a detailed explanation of the potential side-effects. In some cases patients are switched to carboplatin plus paclitaxel because of the toxicity of the ifosfamide regimen; however, data are only available for the metastatic setting [41]. There are currently no valid data on the benefits of adjuvant endocrine therapy.

A randomized study [42] has shown that adjuvant pelvic irradiation (external teletherapy administered at a dose of $50.4 \mathrm{~Gy}$ ) of patients with stage I or II disease resulted in improved local control in the subgroup of patients with carcinosarcoma $(n=92)$, with local recurrence dropping from 47 to $24 \%$ in the observation period (mean follow-up 6.8 years) as well as a trend to improved overall survival, although this trend did not reach statistical significance.

Because of the improved local control, postoperative radiation therapy is indicated in patients with FIGO stage I/II carcinosarcoma.

\subsection{Therapy in the metastatic and recurrent setting} Total resection should be considered for patients with isolated recurrence of disease or metastasis [43].

There are no large phase II or phase III studies in the adjuvant or metastatic setting of mono-chemotherapy regimens for carcinosarcoma because of insufficient therapeutic benefit. Only ifosfamide monotherapy has shown acceptable rates of response of up to $36 \%$ [44]. With regard to combination therapies, the most recent Cochrane analysis showed a significantly lower mortality for ifosfamide combination therapy compared to ifosfamide monotherapy (HR for mortality 0.75; 95\% CI 0.6-0.94) [45]. Based on this analysis, a phase III study [46] demonstrated a significant benefit of combination therapy with ifosfamide and paclitaxel compared to ifosfamide alone for both progression-free and overall survival, indicating that this regimen could be recommended as a potential combination therapy. Another phase III study [44] showed a benefit for a combination of ifosfamide plus cisplatin 
compared to ifosfamide alone only for progression-free survival but not for overall survival, meaning that this relatively toxic combination therapy should be prescribed with caution. Other effective combinations therapies include carboplatin plus paclitaxel and carboplatin plus pegylated liposomal doxorubicin $[41,47,48]$. Percutaneous radiation therapy can be used for the targeted palliative therapy of local and loco-regional recurrence [49]. Percutaneous radiation therapy can also be considered in patients with $\mathrm{R} 1 / \mathrm{R} 2$ resection and local disease as well as in the primary and recurrent setting.

4

\section{Uterine Leiomyosarcoma}

\subsection{Introduction}

The mean age at onset of disease is around 50 years [17]. Clinical symptoms include bleeding disorders and vaginal or abdominal pressure, depending on the size of the lesion; however, most patients are asymptomatic. LMS are therefore usually found incidentally after hysterectomy or enucleation of uterine fibroids. Curettage to determine the cause of bleeding often does not provide sufficient information for a definitive diagnosis or exclusion. Unfortunately, even if there is a suspicion of LMS, there are no specific signs for LMS on imaging (ultrasound, CT, MRI) [50]. Leiomyosarcomas are very aggressive tumors and are associated with a poor prognosis, even if the tumor is still confined to the uterus. According to the rules of the WHO and the Gynecologic Oncology Group, uterine leiomyosarcomas are not staged. The rate of recurrence is between 53 and $71 \%$. A Norwegian study reported a 5-year survival rate of only $51 \%$ for stage I and $25 \%$ for stage II disease [51]. However, this study did show that prognosis for patients with stage I disease depended significantly on tumor size and mitotic index, allowing patients to be separated into 3 risk groups with marked differences in prognosis. As already mentioned above, the overall prognosis for LMS is poor, with a mean 5-year survival rate of 40-50\% [52,53].

Prognosis is slightly better for patients with early-stage disease. According to the biggest study to date by Garg et al. ( $\mathrm{n}=819$ patients), the 5 -year survival rate was $76.6 \%$ for patients with stage IA disease and dropped to just $48.4 \%$ for patients with stage IB disease [11].

Age and tumor stage (tumor size) are significant prognostic factors for LMS $[11,52]$.

Additional prognostic factors discussed in the literature include tumor-free resection margin, mitotic score and vascular invasion [52]. Morcellation is one of the most important negative prognostic factors [18].

\subsection{Histopathological diagnosis}

Leiomyosarcomas (LMS) typically present either as a solitary lesion in the uterus or in combination with leiomyomas, when they are usually the largest lesion in the uterus. Only 25\% of LMS are $<5 \mathrm{~cm}$; two thirds are intramural, $20 \%$ are submucosal, and $10 \%$ are subserosal; 5\% are located in the cervix of the uterus.

The cut surface is typically grayish-white, soft, and gelatinous with foci of necrosis and hemorrhage (variegated cut surface), and lesions are often poorly circumscribed. The cut surface of myxoid LMS is typically myxoid with cystic changes [54].

Histologically, the WHO classification differentiates between (classic) leiomyosarcoma and epithelioid and myxoid type [3]. Infiltrative extension into the adjacent myometrium has been reported for some LMS. The WHO classification requires evidence of mitosis and tumor cell atypia for a diagnosis of LMS [3]. Because differentiating infarctoid necrosis from tumor cell necrosis is difficult, this parameter is not considered absolutely necessary for diagnosis.

The WHO classification does not include a staging system for LMS and other rare sarcomas [3]. The WHO classification divides endometrial stromal sarcoma (ESS) into low-grade and high-grade tumors [3]. Because of their unfavorable prognosis, undifferentiated uterine sarcomas (UUSs) are always classified as high-grade tumors. For extrauterine soft tissue sarcomas, the WHO encourage using the grading system of the Féderation Nationale des Centres de Lutte Contre le Cancer (FNCLCC grading system) [5558] to estimate prognosis and decide on the therapeutic approach, use of which is also recommended by the European Organisation for Research and Treatment of Cancer (EORTC). However, the FNCLCC grading system cannot be readily transferred to uterine LMS and other rare uterine sarcomas. If the healthcare professional treating the patient is requested to classify the lesion according to the FNCLCC grading system, this classification can be included in the report on findings together with the information that currently no predictive or prognostic assessment exists.

\subsection{Surgery}

The gold standard of surgical management consists of total removal of the uterus. The indication for adnexa removal is optional, depending on the patient's menopausal status. The ovaries can be preserved in young women with tumors limited to the uterus $[11,17,59]$. Intraperitoneal morcellation is associated with a worse prognosis; morcellating procedures such as laparoscopic supracervical hysterectomy or laparoscopic uterus-preserving procedure with intraperitoneal morcellation are therefore not recommended when there is a suspicion of sarcoma $[18,60]$.

The incidence of primary pelvic and para-aortic lymph node metastasis is low for LMS. If there is lymph node involvement nodes are often already found to be abnormal at surgery - then hematogenous metastasis is usually already present. In these cases systematic pelvic and para-aortic lymphadenectomy is not associated with a better prognosis and is generally not recommended [61]. Suspect lymph nodes should nevertheless be removed. There is only very limited data on fertility-preserving procedures, and they are therefore not currently recommended. Surgical tumor reduction should be attempted in symptomatic patients with extensive advanced tumors [59].

\subsection{Adjuvant systemic therapy and radiotherapy}

Adjuvant systemic therapy is not generally indicated as, to date, no randomized study has shown a benefit for overall survival. However, based on the existing results of prospective phase II studies and one phase III study, it appears that patients with leiomyosarcoma with disease limited to the uterus (stages I-IIIA with involvement limited exclusively to the uterine serosa) may benefit from systemic therapy after surgery with no residual tumor.

A combination of doxorubicin plus ifosfamide plus cisplatin appears to have a significant positive effect on 3-year progressionfree survival (55\% of the group who had subsequent radiation therapy vs. $41 \%$ in the control group who had radiation therapy alone), but was also associated with significantly higher levels of toxicity [62].

Combination chemotherapy consisting of docetaxel and gemcitabine followed by doxorubicin (3-year PFS 57\%) has been reported to offer similarly good results with a lower toxicity $[63,64]$. 
A comparative phase III study (follow-up compared to gemcitabine combined with docetaxel followed by doxorubicin) is currently being carried out (GOG \#277).

There are no data on the use of adjuvant endocrine therapy to treat uterine leiomyosarcoma.

A randomized study which used adjuvant pelvic irradiation with 50.4 Gy to treat stage I and II uterine sarcomas [42] reported improved local control in the overall patient cohort with different sarcoma entities but found no effect for the rates of local recurrence in the subgroup of patients $(n=99)$ with leiomyosarcoma (local recurrence: $20 \%$ with radiotherapy vs. $24 \%$ without radiotherapy) and no benefit in terms of overall survival. Radiation therapy is therefore not generally indicated after complete resection of stage I/II LMS. Radiation therapy may be considered after $\mathrm{R} 1 / 2$ resection of locally advanced tumor limited to the pelvis.

\subsection{Therapy in the metastatic and recurrent setting} In patients with recurrence or metastasis of uterine leiomyosarcoma only total surgical resection appears to be associated with a better prognosis [65-68]. In every patient with recurrence or isolated metastasis it is therefore important to consider whether and to what extent complete resection is possible or useful. Individual studies have reported improved survival rates for selected patient cohorts (mean survival 45 vs. 31 months or 2.0 vs. 1.1 years) after complete resection of metastases in patients with leiomyosarcoma $[65,69]$. The resection of individual lung and/or liver metastases could prolong survival in selected patients [70, 71]. Several studies reported improved survival after resection of metastases in patients with leiomyosarcoma who had a disease-free interval of more than 6 to 12 months, while incomplete resection was associated with both a shorter disease-free interval and a poorer prognosis.

Only one prospective randomized phase II study which investigated the combination of docetaxel plus gemcitabine showed that combination therapy is superior to mono-chemotherapy in patients with metastatic soft tissue sarcoma [72].

Some combinations have shown higher rates of response compared to mono-chemotherapy in the metastatic setting; however they were also associated with a higher toxicity [73-75].

There are only a few effective substances - ifosfamide, gemcitabine or doxorubicin - for mono-chemotherapy with moderate response rates of between 15 and 25\% [76,77]. Paclitaxel, cisplatin, topotecan and etoposide have also been studied but appear to be insufficiently effective (low response rates of $<10 \%$ ) [78-81]. The use of trabectedin for second-line chemotherapy in the metastatic setting has been studied in phase II trials and should be primarily used to treat patients with asymptomatic metastasis. Although the expected rates of remission are low, improved disease control was reported for up to $50 \%$ of cases [82].

The efficacy of multiple tyrosine kinase inhibitor pazopanib as another potential second-line therapy option has been investigated in a double-blind, placebo-controlled phase III study; however, the study included a range of histologically different sarcoma types in the metastatic setting. The findings for pazopanib were similar to those of trabectedin with regard to remission rates and disease control. The study showed a significant prolongation of the progression-free interval with pazopanib in both the overall patient cohort and the subgroup with leiomyosarcoma [83].

There are no valid data on the primary use of endocrine therapy in these patients, although a few case studies have reported a metastatic response to aromatase inhibitors in patients with es- trogen receptor-positive tumors (letrozole $2.5 \mathrm{mg} / \mathrm{d}$, anastrozole $1 \mathrm{mg} / \mathrm{d}$ ).

Palliative percutaneous radiotherapy has been used to treat patients with loco-regional non-resectable recurrence [49]. Postoperative radiotherapy can also be considered to improve local control in patients with isolated metastasis, although there is no evidence that this will improve overall survival.

\section{$5 \quad$ Low-grade Endometrial Stromal Sarcoma}

\section{$5.1 \quad$ Introduction}

The mean age at onset of disease is the 6th decade of life [17]. In general, these tumors become symptomatic with pathological bleeding, sometimes in association with enlarged uterus and the accompanying symptoms of enlarged uterus. There are no specific diagnostic features for low-grade ESS on any imaging technique (ultrasound, CT, MRI) [50]. The same applies to curettage for abnormal bleeding, a procedure which often leads to incorrect diagnosis (s. above, e.g., intramural tumors) [17]. Tumor stage is the most important prognostic factor for low-grade ESS [84]. The overall disease-specific 5-year survival rate for lowgrade ESS is $80-90 \%$, and the 10 -year survival rate is around $70 \%[85,86]$. If the tumor is limited to the uterus at the time of diagnosis (stage I) the reported rates rise to 100 or $90 \%$. Survival rates for patients with higher stage disease can drop to $40 \%$.

\subsection{Histopathological diagnosis}

In the past, stromal sarcomas were differentiated into low malignancy and highly malignant stromal sarcomas; in the interim period following the WHO classification of 2003 this differentiation was abandoned, but the new WHO classification of 2014 has reverted to this categorization.

These changes in nomenclature make is difficult to unambiguously classify stromal sarcomas discussed in the literature over time. The recommendations in Chapter 4 of this guideline therefore refer to typical low-grade ESS, in contrast to Chapter 5 which summarizes the recommendations for high-grade ESS but also covers undifferentiated uterine sarcoma (UUS), which appears to have a comparable tumor biology.

Low-grade ESS (LG-ESS) are defined as malignant tumors consisting of mesenchymal cells resembling stromal cells of the endometrium in the proliferative phase [3]. The presentation may vary and can include intratumoral hemorrhage and/or necrosis. LG-ESS show myometrial infiltration with or without lymph node involvement, commonly with vascular infiltration; in the latter case tumor expansion can occasionally include extrauterine vessels. Nuclear or cellular polymorphism may be absent or low; mitotic activity may likewise be absent or low.

\subsection{Surgery}

The therapy of choice consists of total hysterectomy (without morcellation) and removal of both adnexa [87].

The endocrine dependence of LG-ESS is well established. A retrospective analysis of 153 LG-ESS patients showed a significantly increased rate of recurrence in premenopausal patients with preservation of the ovaries. However, both this study and two further analyses of the SEER database showed no negative impact on overall survival. It is therefore important to carefully weigh up the benefits of ovarian preservation in younger patients against the risk of a higher probability of recurrence and discuss the issue critically with patients [88, 112-115]. 
There are no data on the oncological safety of estrogen therapy after primary surgery of low-grade ESS with removal of both adnexa in premenopausal women. Estrogen therapy is not recommended because of the tumor biology of low-grade ESS and its high estrogen dependency [116].

Lymph node involvement does not appear to affect prognosis. Thus, neither systematic lymphadenectomy nor subsequent adjuvant therapies appear to prolong survival, meaning that lymphadenectomy should not be recommended as a standard procedure $[50,86,88]$.

It is not clear whether cytoreduction will positively affect survival in patients with advanced tumors [89]. The indication for cytoreduction - potentially with palliative intent - must depend in each case on the patient's clinical symptoms.

\subsection{Adjuvant systemic therapy and radiation therapy}

Postoperative adjuvant endocrine therapy can be discussed with patients who have FIGO stage III disease or higher, although prospective studies are lacking. The data from comparative retrospective analyses of adjuvant therapy support the use of either medroxyprogesterone acetate $200 \mathrm{mg} / \mathrm{d}$ (in Germany only available in dosages of $250 \mathrm{mg}$ ) or megestrol acetate $160 \mathrm{mg} / \mathrm{d}$ or, alternatively, aromatase inhibitor therapy (letrozole $2.5 \mathrm{mg} / \mathrm{d}$, anastrozole $1 \mathrm{mg} / \mathrm{d}$ or exemestane $25 \mathrm{mg} / \mathrm{d}$ ). The duration of adjuvant therapy has not been adequately investigated. A duration of 5 years is being discussed [37].

There are no valid data on the benefits or risks of adjuvant chemotherapy.

A large epidemiological study of 3650 patients with uterine sarcoma carried out in the USA showed a significant positive effect of adjuvant pelvic radiotherapy ( \pm brachytherapy) on loco-regional recurrence-free survival, both for the overall study population [90] and for the subgroup of patients with ESS ( $n=361$; after 5 years: 97 vs. 93\%; after 8 years: 97 vs. 87\%). However, another large epidemiological study of 1010 patients with ESS also carried out in the USA was unable to show a significant benefit of adjuvant radiotherapy for overall survival [86]. In the only relevant randomized study on pelvic radiotherapy for uterine sarcoma [42] which included 30 patients with endometrial stromal sarcoma, survival was not calculated separately for this subgroup. It therefore appears that postoperative radiotherapy only offers moderate improvement of already good loco-regional control in patients with endometrial stromal sarcoma, and this benefit needs to be weighed up carefully against the medium and longterm side-effects.

\subsection{Therapy in the metastatic and recurrent setting} Endometrial stromal sarcomas usually have a better prognosis than leiomyosarcomas. Disease may recur even after several decades [91]. Surgery with the aim of macroscopically complete resection should be considered in patients with recurrent disease or metastasis [43]. Because of the slow growth of this type of cancer, patients with low-grade endometrial stromal sarcoma can benefit from repeated resections [50].

Percutaneous radiotherapy can be used with palliative intent in patients with local or loco-regional recurrence which is not completely resectable $[92,93]$.

Systemic therapy is indicated in patients with postoperative residual tumor, inoperable recurrent disease, or distant metastasis of low-grade endometrial stromal sarcoma. Because of the high expression of estrogen and progesterone receptors known to be present in low-grade endometrial stromal sarcomas, gestagens or aromatase inhibitors are used [94-97].

The retrospective analysis of small case series suggests that medroxyprogesterone acetate $200 \mathrm{mg} / \mathrm{d}$ (in Germany only available in dosages of $250 \mathrm{mg}$ ) or megestrol acetate $160 \mathrm{mg} / \mathrm{d}$ can be highly effective, with reported response rates of up to $82 \%$ [95]. A positive effect has also been reported for aromatase inhibitors (letrozole $2.5 \mathrm{mg} / \mathrm{d}$, anastrozole $1 \mathrm{mg} / \mathrm{d}$ or exemestane $25 \mathrm{mg} / \mathrm{d}$ ) which may offer another alternative, although the data on their use to treat recurrent disease in patients with low-grade ESS is more limited [96].

Chemotherapy should only be used after other options have been exhausted. There are no studies showing the superiority of combination therapy over monotherapy. The current data is based only on case reports and phase II studies in which other uterine sarcomas were also treated $[98,99]$.

\section{$6 \quad$ High-grade Endometrial Stromal Sarcoma and Undifferentiated Uterine Sarcoma}

\subsection{Introduction}

The mean age at onset of disease is around 60 years. The diagnosis is often only made when disease has reached an advanced stage. In general, these tumors become symptomatic through pathological bleeding, sometimes in combination with an enlarged uterus and the accompanying symptoms. Because detection usually only occurs when disease is already well advanced, the prognosis is poor, with a mean overall survival of 1-2 years $[100,101]$. In addition to tumor stage, it has been suggested that age ( $\leq 60$ vs. $>60$ years) may be another prognostic factor for survival and local control [102].

\subsection{Histopathological diagnosis}

High-grade endometrial stromal sarcomas (HG-ESSs) are tumors which arise from the endometrial stroma in the proliferative phase of the endometrium. They are characterized by infiltrative and destructive growth generally extending to the outer half of the myometrium and often with demonstrable extrauterine spread. The majority of HG-ESS show intratumoral (microscopic or macroscopic) necrosis.

Undifferentiated uterine sarcomas (UUSs) are high-grade malignant mesenchymal tumors of the endometrium or myometrium, which bear no resemblance to endometrial stroma and which cannot be assigned to any specific histogenetic type [103]. Morphologically, they are highly polymorphic tumors showing brisk mitotic activity, with numerous atypical mitoses and infiltrativedestructive growth, characterized by rhabdoid and myxoid structure and vascular infiltration [103].

As mentioned above, the term "undifferentiated endometrial sarcoma (UES)", which was still included in the 2003 WHO classification [104], is no longer included in the current WHO classification [3] and should therefore no longer be used.

\subsection{Surgery}

The therapy of choice consists again of total hysterectomy (without morcellation) and bilateral adnexa removal. It is not clear whether the adnexa could be preserved in premenopausal women. Positive pelvic and/or para-aortic lymph nodes are associated with a poorer prognosis, but there is no indication that surgical removal followed by adjuvant treatment will improve this limited prognosis. 
Whether cytoreduction of advanced tumors will improve patient survival is not clear. In contrast to low-grade ESS, a multicenter retrospective analysis showed a positive impact on survival after cytoreduction of high-grade ESS [89].

\subsection{Adjuvant systemic therapy} and radiation therapy

As with low-grade ESS, postoperative adjuvant endocrine therapy can be discussed with patients who have tumors with demonstrable estrogen and/or progesterone receptors, although prospective studies on the benefit of this approach are lacking. Given the unfavorable prognosis of this histological type and the lack of alternative adjuvant therapies, a risk-benefit analysis done in consultation with the patient when the patient is given information on prognosis could include the proposed use of medroxyprogesterone acetate $200 \mathrm{mg} / \mathrm{d}$ (in Germany only available in dosages of $250 \mathrm{mg}$ ) or megestrol acetate $160 \mathrm{mg} / \mathrm{d}$. Alternatively, therapy with an aromatase inhibitor (letrozole $2.5 \mathrm{mg} / \mathrm{d}$, anastrozole $1 \mathrm{mg} / \mathrm{d}$ or exemestane $25 \mathrm{mg} / \mathrm{d}$ ) could be considered. The duration of adjuvant therapy has not been sufficiently studied.

There are no valid data on the benefits and risks of adjuvant chemotherapy, and chemotherapy will have to be discussed on an individual basis.

A multicenter retrospective analysis studied 59 patients with endometrial stromal tumors, of whom $n=29$ had undifferentiated uterine sarcoma (58\% were stage I or II (FIGO 1988) [102]). $86 \%$ of patients received pelvic external-beam radiotherapy (mean dose for the overall cohort was $48 \mathrm{~Gy}$ ) and $51 \%$ received brachytherapy. The 5-year overall survival rate of patients with undifferentiated uterine sarcoma was $65 \%$; loco-regional control was achieved in $40 \%$. Multivariate analysis of the overall group (endometrial stromal sarcoma and undifferentiated uterine sarcoma) showed that pelvic irradiation was associated with significantly higher overall survival. The data on radiotherapy to treat patients with undifferentiated uterine sarcoma is therefore limited.

\subsection{Therapy in the metastatic and recurrent setting}

Although there is only limited data available, as with low-grade ESS endocrine therapy should only be discussed with patients if the tumor has demonstrable estrogen or progesterone receptors. In general, chemotherapy options to treat this tumor entity are similar to those used for other soft tissue sarcomas, for example leiomyosarcoma), although the overall data are limited.

\section{$7 \quad$ Uterine Adenosarcoma}

\subsection{Introduction}

This rare entity can occur in all age groups [105], peaking in the 6th and 7th decade of life. Even more than with other sarcomas, typical presenting symptoms include disorders of the menstrual cycle and of menstrual bleeding, sometimes accompanied by enlarged uterus and corresponding symptoms. The rate of recurrence for adenosarcoma without sarcomatous overgrowth is 15$25 \%$; the rate of recurrence for patients with sarcomatous overgrowth is $45-70 \%$. An increased rate of recurrence has also been observed in patients with deeper myometrial invasion, lymph node invasion, highly malignant heterologous stromal component and/or extrauterine spread. Recurrence occurs predominantly in the pelvic area or the vagina. Distant metastasis (mainly pulmonary metastases) occurs in around $5 \%$ of cases [106]. The mortality for typical adenosarcoma is $10-25 \%$, while mortality for adenosarcoma with sarcomatous overgrowth can rise to $75 \%$. A detailed comparison of more than 500 patients with adenosarcoma and almost 5000 patients with carcinosarcoma showed that patients with adenosarcoma had a significantly better prognosis. The 5-year survival rate for patients with early-stage disease was $79 \%$ and was still $48 \%$ for patients with stage III disease compared to carcinosarcoma where 5-year survival of patients with early-stage disease was only $51 \%$, dropping to $24 \%$ for patients with stage III disease [107].

\subsection{Histopathological diagnosis}

The WHO classification defines adenosarcoma (AS) as a mixed epithelial-mesenchymal tumor of the uterus with benign epithelial and malignant mesenchymal component $[108,109]$. The mesenchymal components have a low-grade histology in $\sim 90 \%$ of cases. If the mesenchymal component corresponds to that of high-grade sarcoma (high-grade polymorphism, higher mitotic rate, possibly with myometrial or cervical stromal invasion or venous invasion and evidence of heterologous elements) and is demonstrably present in $>25 \%$ of the tumor, the diagnosis is AS with sarcomatous overgrowth.

\subsection{Surgery}

As with other sarcomas, hysterectomy without morcellation is the therapy of choice.

It is not clear whether surgery should include removal of the adnexa.

The importance of systematic pelvic and para-aortic lymphadenectomy is also unclear [37].

In cases with advanced disease the aim must be to achieve maximum surgical reduction of the tumor.

\subsection{Adjuvant systemic therapy and radiation therapy}

Very few adenosarcoma have been included in studies on adjuvant therapy for carcinosarcoma/malignant mixed Müllerian tumors of the uterus. Meaningful data, particularly with regard to chemotherapy, is only available for carcinosarcoma. It is not clear to what extent this data can be transferred to adenosarcoma.

\subsection{Therapy in the metastatic and recurrent setting} Because of the lack of data, the proposed surgical approach consists of complete resection in analogy to other uterine sarcomas. Radiotherapy can be used as a palliative therapy for local non-resectable recurrence or postoperatively for isolated findings. There is currently no optimum systemic therapy regimen. Recurrence of adenosarcoma with and without sarcomatous overgrowth has been shown to respond to ifosfamide or doxorubicin-based chemotherapies [110].

\section{$8 \quad$ Follow-up}

Follow-up serves to monitor the success of treatment and the patient's quality of life.

Follow-up of patients based on the respective tumor type must include speculum examination, vaginal and rectal inspection as well as ultrasound, where necessary, and should be carried out at regular intervals.

Whether local intervention to treat early-stage unilocular recurrent lesions results in an improvement of overall survival is not clear (see also the various chapters on individual entities). 
Nevertheless additional imaging procedures can be useful for the early detection of metastasis.

The follow-up of patients should also focus on psychosocial and socio-medical aspects.

Follow-up care also needs to take account of the fact that co-morbidities can affect the severity of short, medium and long-term side-effects of treatment after surgery and/or percutaneous radiotherapy and drug treatment or cytostatic treatment.

\section{Management of Morcellated Sarcoma}

There are no prospective studies in the literature on the appropriate procedure for morcellated sarcoma, only retrospective case collections. The Authors of this guideline therefore agree with the position paper of the German Society for Gynecology and Obstetrics published in August 2014 on the concerns regarding the risk of uterine sarcoma subsequent to morcellation [111]. The position paper provides detailed statements and recommendations.

\section{Patient Information}

Providing the patient with suitable information on the diagnosis, prognosis and proposed treatment for uterine sarcoma is one of the physician's key tasks and forms an important part of physician-patient communication. Communication must aim to establish a relationship of trust and active cooperation between physician and patient. Experience has shown us that patients are interested in being well informed. In general, patients will not receive all the information in a single meeting; informing the patient is an ongoing process. Ideally the information will lead to shared decision-making.

Successful communication of information to patients has a positive impact on compliance, tolerance of side-effects, and patient satisfaction with treatment.

In Germany, the physician's obligations with respect to informing and communicating information to patients was formally laid down in 2013 in a new "law to improve the rights of patients" (PatRechteG, which entered into force on February 26, 2013). The draft bill was accepted by the German Bundestag on November 29, 2012. The law covers the following aspects: the duty of the treating physician and patient to provide information; consent; the obligation to provide detailed information; the documentation of treatment; access to the patient's records; and the burden of proof and liability in cases of malpractice and incorrect medical advice. A number of obligations of a quasi-statutory nature are linked to this new law which go beyond the scope of recommendations provided by a guideline.

The following aspects should be considered when providing information to patients: the information must be provided in an appropriate setting (a pleasant environment free of disturbances, sufficient time must be available). The decision whether to include the patient's partner, family member(s) or a third person lies with the patient. Active listening, expressing empathy and encouraging the patient to express her feelings and ask questions are conducive to conducting the discussion and managing it well.
A number of training programs have been developed for physicians to help them practice patient-centered communication and dealing with difficult communication situations. The information provided to a patient should be detailed, comprehensible (avoiding specialist medical terms where possible), and truthful. It is particularly important to show consideration and respect the patient's information needs and her ability to cope. The discussion must be documented in the patient's records.

Informing only the family members of a patient who has the cognitive capacity to understand is usually illegal, unless the patient has herself expressly agreed to this course of action.

With regard to the diagnosis, the physician must inform the patient truthfully without playing down the severity; nevertheless, depending on the individual patient's condition and stage of disease the discussion should leave enough leeway for hope or palliative care. The physician must ascertain in all cases whether the information has been understood by the patient in the way it was intended. Information and counseling provided to the patient should also include information on the additional assistance available, particularly on the support by psycho-oncologists, pastoral care, or self-help groups. If disease progresses it is important that the necessary truthful information is consistent with communicating hope. If a cure is no longer possible, it can be helpful to show the patient the best possible options to alleviate symptoms.

With regard to the proposed treatment, the principles of treatment in terms of the purpose, type, extent and implementation of treatment, and the benefits along with the risks associated with treatment should be presented to the patient. Alternative treatments, e.g. participation in clinical studies, must be explained. The type of side-effects or possible late sequelae of treatment and their impact on the patient's lifestyle and quality of life must be discussed. The patient must be informed of her right to seek a second opinion. The necessity for oncological follow-up and the options for rehabilitation after treatment has been completed should also be addressed, as should the existing options of psycho-oncological and social welfare support and the benefits of self-help groups.

\section{Affiliations}

${ }^{1}$ Frauenklinik, Hochtaunuskliniken Bad Homburg, Bad Homburg

2 Frauenklinik, Alb Fils Kliniken, Göppingen

${ }^{3}$ Frauenklinik, Klinikum Darmstadt, Darmstadt

${ }^{4}$ Klinik für Gynäkologie und Gynäkologische Onkologie, Klinikum Essen Mitte, Essen

${ }^{5}$ Klinik für Gynäkologie, Geburtshilfe und Reproduktionsmedizin, Universitätsklinikum des Saarlandes, Homburg/Saar

${ }^{6}$ Klinik und Poliklinik für Frauenheilkunde und Geburtshilfe, Universitätsklinikum Köln, Cologne

${ }^{7}$ Klinik und Poliklinik für Gynäkologie, Universitätsklinikum Halle, Halle/Saale

${ }^{8}$ Klinik für Gynäkologie und Geburtshilfe, Martin-Luther-Krankenhaus Berlin, Paul Gerhardt Diakonie, Berlin

${ }^{9}$ Abteilung für Mamma-, Urogenital, und Perinatalpathologie, Institut für Pathologie, Universitätsklinikum Leipzig, Leipzig

10 Institut für Pathologie Mannheim, Mannheim

11 Universitätsklinik und Poliklinik für Strahlentherapie, Universitätsklinikum Halle, Halle/Saale

12 Institut für diagnostische und interventionelle Radiologie, Universitätsklinikum Frankfurt, Frankfurt/Main

13 Klinik für interdisziplinäre Onkologie, Helios Kliniken Berlin-Buch, Berlin

${ }^{14}$ Frauenklinik, Universitätsklinikum Erlangen, Erlangen

${ }^{15}$ Frauenselbsthilfe nach Krebs e. V., Erlangen 


\section{References}

1 Brooks SE, Zhan M, Cote T et al. Surveillance, epidemiology, and end results analysis of 2677 cases of uterine sarcoma 1989-1999. Gynecol Oncol 2004; 93: 204-208

2 Wittekind C, Meyer HJ. TNM-Klassifikation maligner Tumoren. Weinheim: Wiley-VHC Verlag; 2010: 184-187

3 Oliva E, Carcangiu ML, Carinelli SG, Ip P, Loening T, Longacre TA, Nucci MR, Prat J, Zaloudek CJ. Mesenchymal Tumors of the Uterus. In: Kurman RJ, Carcangiu ML, Herrington CS, Young RH, eds. WHO Classification of Tumours of female reproductive Tract. Lyon: IARC Press; 2014: 135147

4 Conklin CM, Longacre TA. Endometrial stromal tumors: the new WHO classification. Adv Anat Pathol 2014; 21: 383-393

5 Fletcher CDM, Bridge JA, Hogendoorn PCW, Mertens F. WHO Classification of soft Tissue and Bone. Lyon: IARC Press; 2013

6 D'Angelo E, Prat J. Uterine sarcomas: a review. Gynecol Oncol 2010; 116: 131-139

7 McCluggage WG. Malignant biphasic uterine tumours: carcinosarcomas or metaplastic carcinomas? J Clin Pathol 2002; 55: 321-325

8 Lopez-Garcia MA, Palacios J. Pathologic and molecular features of uterine carcinosarcomas. Semin Diagn Pathol 2010; 27: 274-286

9 Bansal N, Herzog TJ, Seshan VE et al. Uterine carcinosarcomas and grade 3 endometrioid cancers: evidence for distinct tumor behavior. Obstet Gynecol 2008; 112: 64-70

10 Callister M, Ramondetta LM, Jhingran A et al. Malignant mixed Müllerian tumors of the uterus: analysis of patterns of failure, prognostic factors, and treatment outcome. Int J Radiat Oncol Biol Phys 2004; 58 : 786-796

11 Garg G, Shah JP, Kumar S, et al. Ovarian and uterine carcinosarcomas: a comparative analysis of prognostic variables and survival outcomes. Int J Gynecol Cancer 2010; 20: 888-894

12 Nemani D, Mitra N, Guo M et al. Assessing the effects of lymphadenectomy and radiation therapy in patients with uterine carcinosarcoma: a SEER analysis. Gynecol Oncol 2008; 111: 82-88

13 Buttram VC jr., Reiter RC. Uterine leiomyomata: etiology, symptomatology, and management. Fertil Steril 1981; 36: 433-445

14 Parker WH, Fu YS, Berek JS. Uterine sarcoma in patients operated on for presumed leiomyoma and rapidly growing leiomyoma. Obstet Gynecol 1994; 83: 414-418

15 Liao Q Wang J, Han J. [Clinical and pathological analysis on 106 cases with uterine sarcoma]. Zhonghua Fu Chan Ke Za Zhi 2001; 36: 104107

16 Sreenan JJ, Hart WR. Carcinosarcomas of the female genital tract. A pathologic study of 29 metastatic tumors: further evidence for the dominant role of the epithelial component and the conversion theory of histogenesis. Am J Surg Pathol 1995; 19: 666-674

17 Zaloudek CJ, Hendrickson MR, Soslow RA. Mesenchymal Tumors of the Uterus. In: Kurman RJ, Hedrick Ellenson L, Ronnett BM, eds. Blaustein's Pathology of the female genital Tract. New York, Dodrecht, Heidelberg, London: Springer; 2011

18 Park JY, Park SK, Kim DY et al. The impact of tumor morcellation during surgery on the prognosis of patients with apparently early uterine leiomyosarcoma. Gynecol Oncol 2011; 122: 255-259

19 Santos P, Cunha TM. Uterine sarcomas: clinical presentation and MRI features. Diagn Interv Radiol 2015; 21: 4-9

20 Sadeghi R, Zakavi SR, Hasanzadeh $M$ et al. Diagnostic performance of fluorine-18-fluorodeoxyglucose positron emission tomography imaging in uterine sarcomas: systematic review and meta-analysis of the literature. Int J Gynecol Cancer 2013; 23: 1349-1356

21 Sharma P, Kumar R, Singh H et al. Role of FDG PET-CT in detecting recurrence in patients with uterine sarcoma: comparison with conventional imaging. Nucl Med Commun 2012; 33: 185-190

22 Coffey D, Kaplan AL, Ramzy I. Intraoperative consultation in gynecologic pathology. Arch Pathol Lab Med 2005; 129: 1544-1557

23 Otis $\mathrm{CN}$ et al. Protocol for the examination of specimens from patients with sarcoma. 2013. Online: http://www.cap.org/apps/docs/committees/cancer/cancer_protocols/2013/UterineSarcomaProtocol_3000. pdf; last access: 19.06.2015

24 McCluggage WG, Fisher C, Hirschowitz L. Dataset for histological reporting of uterine sarcomas. 2014. Online: https://www.rcpath.org/ Resources/RCPath/Migrated\%20Resources/Documents/G/G106 UterineSarcomaDataset_Dec14.pdf; last access: 19.06.2015

25 Ehdaivand S, Simon RA, Sung CJ et al. Incidental gynecologic neoplasms in morcellated uterine specimens: a case series with follow-up. Hum Pathol 2014; 45: 2311-2317
26 Horn LC, Schierle K, Schmidt D et al. [Current TNM/FIGO classification for cervical and endometrial cancer as well as malignant mixed müllerian tumors. Facts and background]. Pathologe 2011; 32: 239-243

27 Hedrick Ellenson L, Ronnett BM, Soslow RA, Zaino RJ. Endometrial Carcinoma. In: Kurman RJ, Hedrick Ellenson L, Ronnett BM, eds. Blaustein's Pathology of the female genital Tract. New York, Dodrecht, Heidelberg, London: Springer; 2011

28 Amant F, de la Rey M, Dorfling CM et al. PTEN mutations in uterine sarcomas. Gynecol Oncol 2002; 85: 165-169

29 McCluggage WG, Haller U, Kurman RJ, Kubik-Huch RA. Mixed epithelial and mesenchymal Tumours. In: Tavassoli FA, Devilee P, eds. Pathology and Genetics of Tumours of the Breast and female genital Organs. World Health Organization Classification of Tumours. Lyon: IARC Press; 2003: 245-249

30 Horn LC, Dallacker M, Bilek K. [Carcinosarcomas (malignant mixed Mullerian tumors) of the uterus. Morphology, pathogenetic aspects and prognostic factors]. Pathologe 2009; 30: 292-301

31 Amant F, Moerman P, Davel GH et al. Uterine carcinosarcoma with melanocytic differentiation. Int J Gynecol Pathol 2001; 20: 186-190

32 Baschinsky DY, Niemann TH, Eaton LA et al. Malignant mixed Müllerian tumor with rhabdoid features: a report of two cases and a review of the literature. Gynecol Oncol 1999; 73: 145-150

33 Fukunaga M, Nomura K, Endo Yet al. Carcinosarcoma of the uterus with extensive neuroectodermal differentiation. Histopathology 1996; 29 : 565-570

34 Shokeir MO, Noel SM, Clement PB. Malignant mullerian mixed tumor of the uterus with a prominent alpha-fetoprotein-producing component of yolk sac tumor. Mod Pathol 1996; 9: 647-651

35 Takano M, Shibasaki T, Sato K et al. Malignant mixed Mullerian tumor of the uterine corpus with alpha-fetoprotein-producing hepatoid adenocarcinoma component. Gynecol Oncol 2003; 91: 444-448

36 Park JY, Kim DY, Kim JH et al. The role of pelvic and/or para-aortic lymphadenectomy in surgical management of apparently early carcinosarcoma of uterus. Ann Surg Oncol 2010; 17: 861-868

37 Gadducci A, Cosio S, Romanini A et al. The management of patients with uterine sarcoma: a debated clinical challenge. Crit Rev Oncol Hematol 2008; 65: 129-142

38 Tanner EJ, Leitao MM jr., Garg K et al. The role of cytoreductive surgery for newly diagnosed advanced-stage uterine carcinosarcoma. Gynecol Oncol 2011; 123: 548-552

39 Wolfson AH, Brady MF, Rocereto T et al. A gynecologic oncology group randomized phase III trial of whole abdominal irradiation (WAI) vs. cisplatin-ifosfamide and mesna (CIM) as post-surgical therapy in stage I-IV carcinosarcoma (CS) of the uterus. Gynecol Oncol 2007; 107: 177185

40 Cantrell LA, Havrilesky L, Moore DT et al. A multi-institutional cohort study of adjuvant therapy in stage I-II uterine carcinosarcoma. Gynecol Oncol 2012; 127: 22-26

41 Powell MA, Filiaci VL, Rose PG et al. Phase II evaluation of paclitaxel and carboplatin in the treatment of carcinosarcoma of the uterus: a Gynecologic Oncology Group study. J Clin Oncol 2010; 28: 2727-2731

42 Reed NS, Mangioni C, Malmström H et al.; European Organisation for Research and Treatment of Cancer Gynaecological Cancer Group. Phase III randomised study to evaluate the role of adjuvant pelvic radiotherapy in the treatment of uterine sarcomas stages I and II: an European Organisation for Research and Treatment of Cancer Gynaecological Cancer Group Study (protocol 55874). Eur J Cancer 2008; 44: 808-818

$43 \mathrm{Nam} \mathrm{JH}$. Surgical treatment of uterine sarcoma. Best Pract Res Clin Obstet Gynaecol 2011; 25: 751-760

44 Sutton G, Brunetto VL, Kilgore L et al. A phase III trial of ifosfamide with or without cisplatin in carcinosarcoma of the uterus: a Gynecologic Oncology Group Study. Gynecol Oncol 2000; 79: 147-153

45 Galaal K, van der Heijden E, Godfrey Ket al. Adjuvant radiotherapy and/ or chemotherapy after surgery for uterine carcinosarcoma. Cochrane Database Syst Rev 2013; 2: CD006812

46 Homesley HD, Filiaci V, Markman M et al.; Gynecologic Oncology Group. Phase III trial of ifosfamide with or without paclitaxel in advanced uterine carcinosarcoma: a Gynecologic Oncology Group Study. J Clin Oncol 2007; 25: 526-531

47 du Bois A, Burges A, Meier W et al.; Arbeitsgemeinschaft Gynaekologische Onkologie Studiengruppe Ovarialkarzinom. Pegylated liposomal doxorubicin and carboplatin in advanced gynecologic tumors: a prospective phase I/II study of the Arbeitsgemeinschaft Gynaekologische Onkologie Studiengruppe Ovarialkarzinom (AGO-OVAR). Ann Oncol 2006; 17: $93-96$ 
48 Lacour RA, Euscher E, Atkinson EN et al. A phase II trial of paclitaxel and carboplatin in women with advanced or recurrent uterine carcinosarcoma. Int J Gynecol Cancer 2011; 21: 517-522

49 Dusenbery KE, Potish RA, Judson P. Limitations of adjuvant radiotherapy for uterine sarcomas spread beyond the uterus. Gynecol Oncol 2004; 94: 191-196

50 Amant F, Coosemans A, Debiec-Rychter $M$ et al. Clinical management of uterine sarcomas. Lancet Oncol 2009; 10: 1188-1198

51 Abeler VM, Røyne O, Thoresen S et al. Uterine sarcomas in Norway. A histopathological and prognostic survey of a total population from 1970 to 2000 including 419 patients. Histopathology 2009; 54: 355364

52 Pelmus M, Penault-Llorca F, Guillou L et al. Prognostic factors in earlystage leiomyosarcoma of the uterus. Int J Gynecol Cancer 2009; 19: 385-390

53 Iasonos A, Keung EZ, Zivanovic $O$ et al. External validation of a prognostic nomogram for overall survival in women with uterine leiomyosarcoma. Cancer 2013; 119: 1816-1822

54 King ME, Dickersin GR, Scully RE. Myxoid leiomyosarcoma of the uterus. A report of six cases. Am J Surg Pathol 1982; 6: 589-598

55 Coindre JM. Grading and Staging of Sarcoma. In: Fletcher CDM, Bridge JA, Hogendoorn PCW, Mertens F, eds. WHO Classification of Tumours of soft Tissue and Bone. Lyon: IARC Press; 2013: 17-18

56 Guillou L, Coindre JM, Bonichon F et al. Comparative study of the National Cancer Institute and French Federation of Cancer Centers Sarcoma Group grading systems in a population of 410 adult patients with soft tissue sarcoma. J Clin Oncol 1997; 15: 350-362

57 Deyrup AT, Weiss SW. Grading of soft tissue sarcomas: the challenge of providing precise information in an imprecise world. Histopathology 2006; 48: 42-50

58 Coindre JM. Grading of soft tissue sarcomas: review and update. Arch Pathol Lab Med 2006; 130: 1448-1453

59 Kapp DS, Shin JY, Chan JK. Prognostic factors and survival in 1396 patients with uterine leiomyosarcomas: emphasis on impact of lymphadenectomy and oophorectomy. Cancer 2008; 112: 820-830

60 Perri T, Korach J, Sadetzki S et al. Uterine leiomyosarcoma: does the primary surgical procedure matter? Int J Gynecol Cancer 2009; 19: 257 260

61 Leitao MM, Sonoda Y, Brennan MF et al. Incidence of lymph node and ovarian metastases in leiomyosarcoma of the uterus. Gynecol Oncol 2003: 91: 209-212

62 Pautier P, Floquet A, Gladieff $L$ et al. A randomized clinical trial of adjuvant chemotherapy with doxorubicin, ifosfamide, and cisplatin followed by radiotherapy versus radiotherapy alone in patients with localized uterine sarcomas (SARCGYN study). A study of the French Sarcoma Group. Ann Oncol 2013; 24: 1099-1104

63 Hensley ML, Ishill N, Soslow R et al. Adjuvant gemcitabine plus docetaxel for completely resected stages I-IV high grade uterine leiomyosarcoma: results of a prospective study. Gynecol Oncol 2009; 112: 563-567

64 Hensley ML, Wathen JK, Maki RG et al. Adjuvant therapy for high-grade, uterus-limited leiomyosarcoma: results of a phase 2 trial (SARC005). Cancer 2013; 119: 1555-1561

65 Bernstein-Molho R, Grisaro D, Soyfer Vet al. Metastatic uterine leiomyosarcomas: a single-institution experience. Int J Gynecol Cancer 2010 20: $255-260$

66 Leitao MM, Brennan MF, Hensley $M$ et al. Surgical resection of pulmonary and extrapulmonary recurrences of uterine leiomyosarcoma. Gynecol Oncol 2002; 87: 287-294

67 Levenback C et al. Resection of pulmonary metastases from uterine sarcomas. Gynecol Oncol 1992; 45: 202-205

68 Weiser MR, Downey RJ, Leung DH et al. Repeat resection of pulmonary metastases in patients with soft-tissue sarcoma. J Am Coll Surg 2000; 191: 184-190; discussion 190-191

69 Giuntoli RL 2nd, Garrett-Mayer E, Bristow RE et al. Secondary cytoreduction in the management of recurrent uterine leiomyosarcoma. Gynecol Oncol 2007: 106: 82-88

70 Anraku M, Yokoi K, Nakagawa K et al.; Metastatic Lung Tumor Study Group of Japan. Pulmonary metastases from uterine malignancies: results of surgical resection in 133 patients. J Thorac Cardiovasc Surg 2004; 127: 1107-1112

71 Chen H, Pruitt A, Nicol TL et al. Complete hepatic resection of metastases from leiomyosarcoma prolongs survival. J Gastrointest Surg 1998; 2: $151-155$
72 Maki RG, Wathen JK, Patel SR et al. Randomized phase II study of gemcitabine and docetaxel compared with gemcitabine alone in patients with metastatic soft tissue sarcomas: results of sarcoma alliance for research through collaboration study 002 [corrected]. J Clin Oncol 2007; 25: 2755-2763

73 Sutton G, Blessing JA, Malfetano JH. Ifosfamide and doxorubicin in the treatment of advanced leiomyosarcomas of the uterus: a Gynecologic Oncology Group study. Gynecol Oncol 1996; 62: 226-229

74 Hensley ML, Maki R, Venkatraman E et al. Gemcitabine and docetaxel in patients with unresectable leiomyosarcoma: results of a phase II trial. J Clin Oncol 2002; 20: 2824-2831

75 Gupta AA, Yao X, Verma S et al.; Sarcoma Disease Site Group and the Gynecology Cancer Disease Site Group. Systematic chemotherapy for inoperable, locally advanced, recurrent, or metastatic uterine leiomyosarcoma: a systematic review. Clin Oncol (R Coll Radiol) 2013; 25: 346-355

76 Sutton GP, Blessing JA, Barrett RJ et al. Phase II trial of ifosfamide and mesna in leiomyosarcoma of the uterus: a Gynecologic Oncology Group study. Am J Obstet Gynecol 1992; 166: 556-559

77 Look KY, Sandler A, Blessing JA et al.; Gynecologic Oncology Group (GOG) Study. Phase II trial of gemcitabine as second-line chemotherapy of uterine leiomyosarcoma: a Gynecologic Oncology Group (GOG) Study. Gynecol Oncol 2004; 92: 644-647

78 Thigpen T, Blessing JA, Yordan E et al. Phase II trial of etoposide in leiomyosarcoma of the uterus: a Gynecologic Oncology Group study. Gynecol Oncol 1996; 63: 120-122

79 Rose PG, Blessing JA, Soper JT et al. Prolonged oral etoposide in recurrent or advanced leiomyosarcoma of the uterus: a gynecologic oncology group study. Gynecol Oncol 1998; 70: 267-271

80 Miller DS, Blessing JA, Kilgore LC et al. Phase II trial of topotecan in patients with advanced, persistent, or recurrent uterine leiomyosarcomas: a Gynecologic Oncology Group Study. Am J Clin Oncol 2000; 23: 355-357

81 Gallup DG, Blessing JA, Andersen W et al. Evaluation of paclitaxel in previously treated leiomyosarcoma of the uterus: a gynecologic oncology group study. Gynecol Oncol 2003; 89: 48-51

82 Demetri GD, Chawla SP, von Mehren $M$ et al. Efficacy and safety of trabectedin in patients with advanced or metastatic liposarcoma or leiomyosarcoma after failure of prior anthracyclines and ifosfamide: results of a randomized phase II study of two different schedules. J Clin Oncol 2009; 27: 4188-4196

83 van der Graaf WT, Blay JY, Chawla SP et al.; EORTC Soft Tissue and Bone Sarcoma Group; PALETTE study group. Pazopanib for metastatic softtissue sarcoma (PALETTE): a randomised, double-blind, placebo-controlled phase 3 trial. Lancet 2012; 379: 1879-1886

84 Chew I, Oliva E. Endometrial stromal sarcomas: a review of potential prognostic factors. Adv Anat Pathol 2010; 17: 113-121

85 Chang KL, Crabtree GS, Lim-Tan SK et al. Primary uterine endometrial stromal neoplasms. A clinicopathologic study of 117 cases. Am J Surg Pathol 1990; 14: 415-438

86 Barney B, Tward JD, Skidmore T et al. Does radiotherapy or lymphadenectomy improve survival in endometrial stromal sarcoma? Int J Gynecol Cancer 2009; 19: 1232-1238

87 Einstein MH, Barakat RR, Chi DS et al. Management of uterine malignancy found incidentally after supracervical hysterectomy or uterine morcellation for presumed benign disease. Int J Gynecol Cancer 2008; 18: $1065-1070$

88 Shah JP, Bryant CS, Kumar S et al. Lymphadenectomy and ovarian preservation in low-grade endometrial stromal sarcoma. Obstet Gynecol 2008; 112: 1102-1108

89 Leath CA 3rd, Huh WK, Hyde Jjr. et al. A multi-institutional review of outcomes of endometrial stromal sarcoma. Gynecol Oncol 2007; 105: 630-634

90 Sampath S, Schultheiss TE, Ryu JK et al. The role of adjuvant radiation in uterine sarcomas. Int J Radiat Oncol Biol Phys 2010; 76: 728-734

91 Piver MS, Rutledge FN, Copeland $L$ et al. Uterine endolymphatic stromal myosis: a collaborative study. Obstet Gynecol 1984; 64: 173-178

92 Weitmann HD, Knocke TH, Kucera $\mathrm{H}$ et al. Radiation therapy in the treatment of endometrial stromal sarcoma. Int J Radiat Oncol Biol Phys 2001; 49: 739-748

93 Kortmann B, Reimer T, Gerber B et al. Concurrent radiochemotherapy of locally recurrent or advanced sarcomas of the uterus. Strahlenther Onkol 2006; 182: 318-324 
94 Cheng X, Yang G, Schmeler KM et al. Recurrence patterns and prognosis of endometrial stromal sarcoma and the potential of tyrosine kinase-inhibiting therapy. Gynecol Oncol 2011; 121: 323-327

95 Dahhan T, Fons G, Buist MR et al. The efficacy of hormonal treatment for residual or recurrent low-grade endometrial stromal sarcoma. A retrospective study. Eur J Obstet Gynecol Reprod Biol 2009; 144: 8084

96 Maluf FC, Sabbatini P, Schwartz L et al. Endometrial stromal sarcoma: objective response to letrozole. Gynecol Oncol 2001; 82: 384-388

97 Pink D, Lindner T, Mrozek A et al. Harm or benefit of hormonal treatment in metastatic low-grade endometrial stromal sarcoma: single center experience with 10 cases and review of the literature. Gynecol Oncol 2006; 101: 464-469

98 Harter $P$, Canzler U, Lueck $H$ et al. Pegylated liposomal doxorubicin and carboplatin in malignant mixed epithelial mesenchymal and mesenchymal gynecologic tumors: A phase II trial of the AGO study group. J Clin Oncol 2011; 29 (Suppl.): Abstr. 5093

99 du Bois A, Pfisterer J, Burchardi N et al.; Arbeitsgemeinschaft Gynäekologische Onkologie Studiengruppe Ovarialkarzinom; Kommission Uterus. Combination therapy with pegylated liposomal doxorubicin and carboplatin in gynecologic malignancies: a prospective phase II study of the Arbeitsgemeinschaft Gynäkologische Onkologie Studiengruppe Ovarialkarzinom (AGO-OVAR) and Kommission Uterus (AGO-K-Ut). Gynecol Oncol 2007; 107: 518-525

100 Malouf GG, Lhommé C, Duvillard P et al. Prognostic factors and outcome of undifferentiated endometrial sarcoma treated by multimodal therapy. Int J Gynaecol Obstet 2013; 122: 57-61

101 Tanner EJ, Garg K, Leitao MM jr. et al. High grade undifferentiated uterine sarcoma: surgery, treatment, and survival outcomes. Gynecol Oncol 2012; 127: 27-31

102 Schick U, Bolukbasi Y, Thariat J et al. Outcome and prognostic factors in endometrial stromal tumors: a Rare Cancer Network study. Int J Radiat Oncol Biol Phys 2012; 82: e757-e763

103 Oliva E. Cellular mesenchymal tumors of the uterus: a review emphasizing recent observations. Int J Gynecol Pathol 2014; 33: 374-384

104 Hendrickson MA, Tavassoli FA, Kempson RL, McCluggage WG, Haller U, Kubik-Huch RA. Mesenchymal Tumors and related Lesions. In: Tavassoli FA, Devilee P, eds. Pathology and Genetics of Tumours of the Breast and female genital Organs. World Health Organization Classification of Tumours. Lyon: IARC Press; 2003: 233-249
105 Fleming NA, Hopkins L, de Nanassy J et al. Mullerian adenosarcoma of the cervix in a 10-year-old girl: case report and review of the literature. J Pediatr Adolesc Gynecol 2009; 22: e45-e51

106 Clement PB, Scully RE. Mullerian adenosarcoma of the uterus: a clinicopathologic analysis of 100 cases with a review of the literature. Hum Pathol 1990; 21: 363-381

107 Arend R, Bagaria M, Lewin SN et al. Long-term outcome and natura history of uterine adenosarcomas. Gynecol Oncol 2010; 119: 305308

108 McCluggage WG. Mullerian adenosarcoma of the female genital tract. Adv Anat Pathol 2010; 17: 122-129

109 Wells M, Oliva E, Palacios J, Prat J. Mixed epithelial and mesenchymal Tumors of the Uterus. In: Kurman RJ, Carcangiu ML, Herrington CS, Young RH, eds. WHO Classification of Tumours of female reproductive Tract. Lyon: IARC Press; 2014: 148-151

110 Tanner EJ, Toussaint T, Leitao MM jr. et al. Management of uterine adenosarcomas with and without sarcomatous overgrowth. Gynecol Oncol 2013; 129: 140-144

111 Beckmann MW, Juhasz-Böss I, Denschlag D et al. Surgical methods for the treatment of uterine fibroids - risk of uterine sarcoma and problems of morcellation: position paper of the DGGG. Geburtsh Frauenheilk 2015; 75: 148-164

112 Chan JK, Kawar NM, Shin JYet al. Endometrial stromal sarcoma: a population-based analysis. Br J Cancer 2008; 99: 1210-1215

113 Bai H, Yang J, Cao D et al. Ovary and uterus-sparing procedures for low-grade endometrial stromal sarcoma: a retrospective study of 153 cases. Gynecol Oncol 2014; 132: 654-660

114 Amant F, De Knijf A, Van Calster B et al. Clinical study investigating the role of lymphadenectomy, surgical castration and adjuvant hormonal treatment in endometrial stromal sarcoma. Br J Cancer 2007; 97: 1194-1199

115 Beck TL, Singhal PK, Ehrenberg HM et al. Endometrial stromal sarcoma: analysis of recurrence following adjuvant treatment. Gynecol Oncol 2012; 125: 141-144

116 Chu MC, Mor G, Lim C et al. Low-grade endometrial stromal sarcoma: hormonal aspects. Gynecol Oncol 2003; 90: 170-176 


\section{Statements and Recommendations}

\subsection{Incidence, tumor typing or classification and staging}

Uterine sarcomas are a heterogeneous group of rare malignancies $(1.5-3 / 100000)$ of the uterine musculature, endometrial stroma, or uterine connective tissue.

The terms and morphological findings for uterine sarcomas should be based on the currently valid edition of the WHO classification.

Postoperative staging of uterine sarcomas must be based on the currently valid pTNM classification and FIGO classification.

\subsection{Diagnosis}

There are no specific symptoms for uterine sarcoma.

Vaginal ultrasound is the imaging method of choice to investigate suspicion of uterine sarcoma.

Imaging procedures and diagnostic surgery cannot exclude uterine sarcoma.

When uterine sarcoma has been verified histologically, this finding should be followed by computer tomography of the thorax and abdomen because of the high potential for metastasis.

A patient with a diagnosis of uterine sarcoma should be presented to an interdisciplinary tumor board.

\section{Carcinosarcoma}

Therapy of early-stage disease must consist of complete resection of the uterus without morcellation but with bilateral adnexa removal.

This should be complemented by systematic pelvic and para-aortic lymphadenectomy.

Adjuvant chemotherapy can be administered to patients with carcinosarcoma.

Postoperative radiotherapy should be done if the carcinosarcoma is FIGO stage I or II to improve local control.

\section{$4 \quad$ Leiomyosarcoma}

Therapy of early-stage disease consists of complete resection of the uterus without morcellation but with bilateral adnexa removal.

The ovaries can be preserved in selected premenopausal patients. Systematic pelvic and para-aortic lymphadenectomy should not be carried out if lymph nodes are diagnostically unremarkable.

Adjuvant chemotherapy should not be offered to all patients but can be discussed in individual patients depending on the presence of other risk factors (e.g. higher tumor stage).

Radiotherapy should not be carried out after complete resection of a stage I/II LMS.

In the event of recurrence or isolated metastasis the patient should be assessed to determine whether surgery or local treatment is indicated.

\section{$5 \quad$ Low-grade Endometrial Stromal Sarcoma}

Therapy of early-stage disease consists of complete resection of the uterus without morcellation but with bilateral adnexa removal.

No systematic pelvic and para-aortic lymphadenectomy should be done in patients with unremarkable lymph nodes.

Adjuvant endocrine therapy should not be offered to all patients but can be discussed in individual patients depending on the presence of other risk factors (e.g. higher tumor stage).

Adjuvant chemotherapy should not be carried out.

Adjuvant radiotherapy should not be carried out after complete resection.

In the event of recurrence or isolated metastasis the patient should be assessed to determine whether surgery or local treatment is indicated.

There are no data on the oncologic safety of hormone replacement therapy after primary treatment of low-grade ESS. Because of the tumor biology of low-grade ESS with its high estrogen dependency hormone replacement treatment is not recommended.

\section{$6 \quad$ High-grade Endometrial Stromal Sarcoma and Undifferentiated Uterine Sarcoma}

Therapy of early-stage disease must consist of complete resection of the uterus without morcellation but with bilateral adnexa removal.

Systematic pelvic and para-aortic lymphadenectomy should not be carried out in patients with diagnostically unremarkable lymph nodes.

Adjuvant therapy can be administered.

\section{Follow-up}

In the first 2-3 years after primary therapy regular follow-up is necessary at an interval of every 3 months and should include speculum examination, vaginal and rectal inspection and ultrasound, where necessary.

Additional imaging procedures for the early detection of metastasis can be useful.

\section{Patient Information}

The patient should be offered the possibility to include their partner or family members in the meetings and discussions with healthcare professionals.

The patient should be informed about the possibility of contacting self-help groups.

The patient should be offered psychosocial and psycho-oncological support for psychological, sexual or relationship problems. 


\section{Guideline Program}

\section{Editors}

Leading Professional Medical Associations

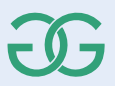

German Society of Gynecology and Obstetrics (Deutsche Gesellschaft für Gynäkologie und Geburtshilfe e. V. [DGGG])

Head Office of DGGG and Professional Societies Hausvogteiplatz 12

DE-10117 Berlin

info@dggg.de

http://www.dggg.de/

\section{President of DGGG}

Prof. Dr. med. Diethelm Wallwiener

Universitätsfrauenklinik Tübingen

Calwerstraße 7

DE-72076 Tübingen

DGGG Guidelines Representative

Prof. Dr. med. Matthias W. Beckmann

Universitätsklinikum Erlangen-Nürnberg

Frauenklinik

Universitätsstraße 21-23

DE-91054 Erlangen

\section{Guidelines Coordination}

Dr. med. Paul Gaß, Tobias Brodkorb, Marion Gebhardt

Universitätsklinikum Erlangen-Nürnberg

Frauenklinik

Universitätsstraße 21-23

DE-91054 Erlangen

fk-dggg-leitlinien@uk-erlangen.de

http://www.dggg.de/leitlinienstellungnahmen

\section{OEGGG}

Austrian Society of Gynecology and Obstetrics (Österreichische Gesellschaft für Gynäkologie und Geburtshilfe [OEGGG])

Innrain 66A

AT-6020 Innsbruck

stephanie.leutgeb@oeggg.at

http://www.oeggg.at

President of OEGGG

Prof. Dr. med. Uwe Lang

Universitätsklinik für Frauenheilkunde und Geburtshilfe Graz

Auenbruggerplatz 14

AT-8036 Graz

OEGGG Guidelines Representative

Prof. Dr. med. Karl Tamussino

Universitätsklinik für Frauenheilkunde

und Geburtshilfe Graz

Auenbruggerplatz 14

AT-8036 Graz

\section{gynécologie}

suisse

Swiss Society of Gynecology and Obstetrics

(Schweizerische Gesellschaft für Gynäkologie

und Geburtshilfe [SGGG])

Gynécologie Suisse SGGG

Altenbergstraße 29

Postfach 6

CH-3000 Bern 8

sekretariat@sggg.ch

http://www.sggg.ch/

President of SGGG

Dr. med. David Ehm

FMH für Geburtshilfe und Gynäkologie

Nägeligasse 13

CH-3011 Bern

SGGG Guidelines Representative

Prof. Dr. med. Daniel Surbek

Universitätsklinik für Frauenheilkunde

Geburtshilfe und feto-maternale Medizin

Inselspital Bern

Effingerstraße 102

CH-3010 Bern
The name of the author U. Ullrich has been revised,

the correct notation is U. Ulrich. 